\title{
Amelogenesis imperfecta
}

INSERM

\section{Source}

INSERM. (1999). Orphanet: an online rare disease and orphan drug data base.

Amelogenesis imperfecta. ORPHA:88661

Amelogenesis imperfecta (AI) represents a group of developmental conditions affecting the structure and clinical appearance of the enamel of all or nearly all the teeth in a more or less equal manner, and which may be associated with morphologic or biochemical changes elsewhere in the body. 